\title{
Erratum to: Outcomes of Modified Harrington Reconstructions for Nonprimary Periacetabular Tumors: An Effective and Inexpensive Technique
}

Nicholas M. Bernthal, MD'1, Shawn L. Price, $\mathrm{MD}^{2}$, Michael J. Monument, $\mathrm{MD}^{3}$, Brandon Wilkinson, $\mathrm{BS}^{3}$, Kevin B. Jones, $\mathrm{MD}^{3}$, and R. Lor Randall, MD, FACS ${ }^{3}$

${ }^{1}$ Department of Orthopaedic Surgery, David Geffen School of Medicine at UCLA, Los Angeles, CA; ${ }^{2}$ Norton Cancer Institute, Louisville, KY; ${ }^{3}$ Sarcoma Services, Department of Orthopaedics, Huntsman Cancer Institute, University of Utah, Salt Lake City, UT

\section{ERRATUM TO: ANN SURG ONCOL}

DOI 10.1245/S10434-015-4507-2

In the initial online publication, R. Lor Randall's middle name erroneously appeared as part of his family name. The name has been corrected in the publication as shown in this erratum.

The online version of the original article can be found under doi:10. 1245/s10434-015-4507-2.

(C) Society of Surgical Oncology 2015

Published Online: 8 April 2015

R. L. Randall, MD, FACS

e-mail: r.lor.randall@hsc.utah.edu 